\title{
Characterization and discrimination of nasopharyngeal carcinoma and nasopharyngeal normal cell lines using confocal Raman microspectroscopy
}

\author{
Yuhuang Ye ${ }^{\mathrm{a}, \mathrm{b}, *}$, Yang Chen ${ }^{\mathrm{a}, \mathrm{b}, *}$, Yongzeng $\mathrm{Li}^{\mathrm{a}}$, Ying $\mathrm{Su}^{\mathrm{c}}$, Changyan Zou ${ }^{\mathrm{c}}$, Yanping Chen ${ }^{\mathrm{c}}$, \\ Lin $\mathrm{Ou}^{\mathrm{a}}$, Rong Chen ${ }^{\mathrm{a}, * *}$ and Haishan Zeng ${ }^{\mathrm{d}}$ \\ ${ }^{a}$ Key Laboratory of Optoelectronic Science and Technology for Medicine, Ministry of Education, \\ Fujian Normal University, Fuzhou, Fujian, China \\ ${ }^{\mathrm{b}}$ College of Physics and Information, Fuzhou University, Fuzhou, Fujian, China \\ ${ }^{\mathrm{c}}$ Fujian Provincial Tumor Hospital, Fuzhou, Fujian, China \\ ${ }^{\mathrm{d}}$ Cancer Imaging Department, British Columbia Cancer Research Centre, Vancouver, BC, Canada
}

\begin{abstract}
Raman microspectroscopy can provide molecular-level information about the biochemical composition and structure of cells and tissues with excellent spatial resolution. In this study, Raman spectroscopy of individual cells from nasopharyngeal carcinoma cell lines C666-1, CNE2 and nasopharyngeal normal cell line NP69 are investigated for their differences. The spectral intensity ratio at 1449 and $1657 \mathrm{~cm}^{-1}$ with a decision line of $\mathrm{I}_{1449} / \mathrm{I}_{1657}=1.10$ can very easily separate the tumor and normal cell lines into two groups. Principal component analysis (PCA) and linear discriminant analysis (LDA) are also used to classify different cell lines and achieved a specificity and sensitivity of 100 and 90\%, respectively. The results support the potential utility of Raman spectroscopy for nasopharyngeal diagnosis.

Keywords: Confocal Raman microspectroscopy, nasopharyngeal carcinoma cells, principal component analysis
\end{abstract}

\section{Introduction}

Raman spectroscopy (RS) is an optical technique that utilizes molecular-specific, inelastic scattering of light photons to interrogate biological materials [5,6]. When the incident light interacts with the material, a small portion of the incident photons are inelastic scattered by interaction with the bonds resulting in a shift toward different frequencies comparing to the original laser light, known as 'Raman shift' [2,4]. RS allows noninvasive and nondestructive detection of biological samples like cell, nucleic acid, tissue and so on without any special preparation or labeling. Unlike infrared spectroscopy, RS has a weak water signature which makes it very conformable for biological samples' analysis [11].

\footnotetext{
*Yuhuang Ye and Yang Chen are co-first authors; they contributed equally to the work.

** Corresponding author: Prof. Rong Chen, Key Laboratory of Optoelectronic Science and Technology for Medicine, Ministry of Education and Fujian Provincial Key Laboratory for Photonics Technology, Fujian Normal University, Fuzhou 350007, China. Tel.: +86 5918348 9919; Fax: +86 5918346 5373; E-mail: chenr@fjnu.edu.cn.
} 
An original study of single living cells and chromosomes has shown that RS could be an ideal optical technique for nondestructive detection of biological samples [18]. From then on, during the past two decades, RS has been widely used in various biological samples especially in tumor cells' study. Differences between normal and abnormal human cell lines (human breast epithelial cells; tumorogenic bone cells, lymphocytes, etc. $[1,2,15,22]$ ) have been characterized from Raman spectra profiles by arrays of fingerprint assignments of physical vibration mode or combining with various multivariate statistical analysis methods like principal component analysis (PCA), linear discriminant analysis (LDA), cluster analysis (CA), etc. All of these studies have proved RS is a powerful tool for cancer detection. But to our knowledge, there are very few reports on the discrimination of human nasopharyngeal carcinoma (NPC) and nasopharyngeal normal cell lines using RS [21]. In the present work, RS were used to characterize and classify NPC cell lines, C666-1, CNE2 and nasopharyngeal normal cell line, NP69. Multivariate analysis of the obtained spectra will be used to differentiate the cancer cells from the normal cells.

\section{Materials and methods}

\subsection{Sample preparation}

Three cell lines were chosen to represent the spectrum of neoplastic development in the nasopharynx. Human NPC cell lines C666-1 (Tai Sheng Biotech, Guangzhou, China) and CNE2 (Fujian Provincial Tumor Hospital, Fuzhou, China) were cultured in RPMI-1640 medium supplemented with 100 U/ml streptomycin, $100 \mathrm{U} / \mathrm{ml}$ penicillin and 10\% Newborn Calf Serum (Invitrogen Corporation, USA). Normal nasopharyngeal cell line NP69 (Xiang Ya Central Experiment Laboratory, Changsha, China) was cultured in Keratinocyte-SFM medium (Invitrogen Corporation, USA). All the cells were grown in an incubator humidified $5 \% \mathrm{CO}_{2}$ atmosphere at $37^{\circ} \mathrm{C}$. All the cells were suspended in the corresponding medium to maintain the cells' activity prior to Raman measurement in a logarithmic growth phase.

\subsection{RS of single cells}

The cell suspension was deposited on pure aluminum flake, where Raman spectra of different cells were recorded using a Renishaw InVia micro-Raman system with a $50 \times$ objective. A multi-element $785 \mathrm{~nm}$ diode laser (about $20 \mathrm{~mW}$ of power) is used for excitation and the Raman spectra of single cell are acquired with the integration time of $20 \mathrm{~s}$ from 300 to $3200 \mathrm{~cm}^{-1}$. Such power and excitation wavelength would not result in any notable cell degeneration [22]. Good signal-to-noise is achieved under these conditions and all the spectra of the same cell lines are averaged to obtain the mean spectra and further used in PCA/LDA analysis.

\subsection{Data analysis}

Thirty, thirty-one and forty-six Raman spectra were obtained from NPC cell lines C666-1, CNE2 and nasopharyngeal normal cell line NP69, respectively. All the spectra were extracted by background autofluorescence subtraction using the Vancouver Raman Algorithm, BC Cancer Agency and University of British Columbia [23], averaged and finally normalized to the area under the curve. Then PCA and LDA are used to analyze the entire Raman spectra and perform classifications. 


\section{Results and discussion}

\subsection{Raman spectra of single tumor and normal cells}

Good quality and representative Raman spectra were obtained from each cell line, as shown in Fig. 1. The three Raman spectra exhibit almost a similar spectral profile with subtle differences which indicates they are composed of the same components with variation occurring in the intensity/intensity ratio of certain band as discussed in detail below. Comparing with normal cell - NP69, the intensity of the band of $1003 \mathrm{~cm}^{-1}$ assigned to phenylalanine is stronger in NPC cells, C666-1 and CNE2. Band positions and its corresponding assignments are shown in Table 1.

According to Table 1, comparing tumor cell lines to normal cell line, it seems that a blue-shift of $3 \mathrm{~cm}^{-1}$ is observed at $2931 \mathrm{~cm}^{-1}$ assigned to $\mathrm{CH}_{3}$ stretching mode. For tumor cell lines, band located at $1043 \mathrm{~cm}^{-1}$ assigned to L-glutamate is missing, which may be too weak to be detected. In addition, the intensity ratio of $\mathrm{I}_{1449} / \mathrm{I}_{1658}$ for the three cell lines were calculated and analyzed as shown in Fig. 2 . Very interestingly, the ratio of $\mathrm{I}_{1449} / \mathrm{I}_{1657}(=1.10)$ seems able to separate tumor and normal cell lines into two groups. $T$-test analysis further confirmed this difference $(p<0.05)$. This result is consistent with a reported Raman spectroscopy study of normal and malignant bronchial tissues [10].

\subsection{Multivariate analysis $P C A / L D A$}

Principal component analysis was conducted on the obtained Raman spectra. A scattered diagram using the first two (about $67.6 \%$ of total variance) and the first three PCs (about $78.6 \%$ of total variance) where $p<0.05$ under $T$-test are generated to show groups of different cell lines, respectively (Fig. 3). It demonstrated good separations between tumor cell lines and normal cell lines, suggesting that there are inherent molecular differences between tumor and normal cell lines.

Multivariate data reduction combined with discriminant analysis was then found to be capable of accounting for the subtle differences between the species. Initially, 10 spectra from C666-1, 10 spectra from CNE2 and 10 spectra from NP69 cell lines, were randomly excluded to be used later as a validation

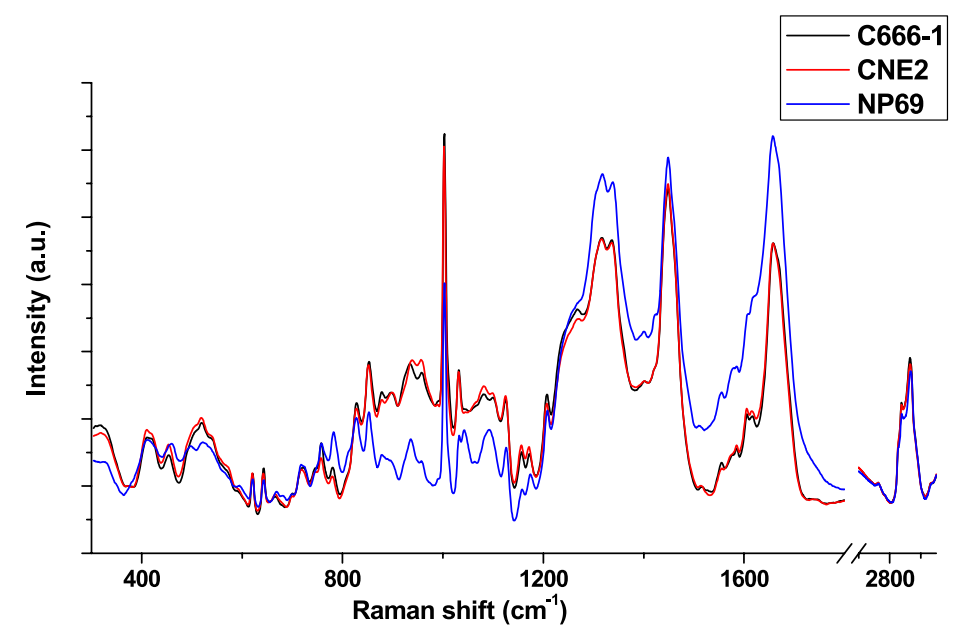

Fig. 1. Average Raman spectra measured from each of the cell lines using $785 \mathrm{~nm}$ laser ranging from 300 to $3200 \mathrm{~cm}^{-1}, 20 \mathrm{~s}$ of integration time; break between 1800 and $2600 \mathrm{~cm}^{-1}$ is due to the lack of informative Raman bands. (Colors are visible in the online version of the article; http://dx.doi.org/10.3233/SPE-2011-0511.) 
Table 1

Band assignments for Raman spectra of C666-1, CNE2 and NP69 cell lines

\begin{tabular}{|c|c|c|c|}
\hline \multicolumn{3}{|c|}{ Band $\left(\mathrm{cm}^{-1}\right)$} & \multirow[t]{2}{*}{ Assignments } \\
\hline C666-1 & CNE2 & NP69 & \\
\hline 621 & 620 & 621 & Phe. [18] \\
\hline 643 & 642 & 643 & $\mathrm{C}-\mathrm{C}$ twist, Tyr. [12] \\
\hline 721 & 718 & 717 & A [20] \\
\hline 758 & 757 & 758 & $\mathrm{~T}[18]$ \\
\hline 780 & 780 & 782 & $\mathrm{C} / \mathrm{U}$ ring br. [19] \\
\hline 828 & 828 & 828 & $\mathrm{O}-\mathrm{P}-\mathrm{O}^{-}[4]$ \\
\hline 853 & 852 & 852 & Tyr., C-C ske. modes [19] \\
\hline 879 & 879 & 878 & L-proline [7] \\
\hline 935 & 939 & 936 & $\alpha$-helix, C-C ske. modes [19] \\
\hline 1003 & 1002 & 1003 & Phe. [13] \\
\hline \multirow[t]{2}{*}{1031} & 1031 & 1032 & Phe., C-N str. [2] \\
\hline & & 1043 & G [7] \\
\hline 1081 & 1081 & 1081 & $\mathrm{O}-\mathrm{P}-\mathrm{O}^{-}[18]$ \\
\hline 1125 & 1125 & 1126 & $\mathrm{C}-\mathrm{N}, \mathrm{C}-\mathrm{C}$ str. [16] \\
\hline 1157 & 1157 & 1158 & C-C, C-N str. [3] \\
\hline 1173 & 1171 & 1174 & Tyr, Phe, C-H bend [3] \\
\hline 1207 & 1207 & 1208 & A, T, amide III [1] \\
\hline 1317 & 1316 & 1318 & $\mathrm{G}[17]$ \\
\hline 1337 & 1337 & 1339 & A, G, C-H def. [3] \\
\hline 1449 & 1449 & 1449 & C-H def. [16] \\
\hline 1606 & 1605 & 1609 & Phe., Tyr. [19] \\
\hline 1658 & 1658 & 1657 & Amide I [13] \\
\hline 2724 & 2724 & 2724 & $\mathrm{COOH}[9]$ \\
\hline 2876 & 2875 & 2878 & $\mathrm{CH}_{2}$ str. [14] \\
\hline 2931 & 2931 & 2934 & $\mathrm{CH}_{3}$ str. [8] \\
\hline 3068 & 3070 & 3068 & $(\mathrm{C}=\mathrm{C}-\mathrm{H})_{\text {arom }}$ str. [14] \\
\hline
\end{tabular}

Notes: str. - stretching, Phe. - phenylalanine, br. - breathing, Tyr. - tyrosine, sym. - symmetric, ske. - skeletal, def. - deformation vibration, A - adenine, $\mathrm{C}$ - cytosine, $\mathrm{G}$ - guanine, $\mathrm{T}$ - thymine, arom. - aromatic.

set and the remainders were used as a training set for the LDA algorithm. Once trained, the validation spectra were fed into the LDA model to determine its ability to correctly identify unknown spectra. The scatter plot of the coefficient of each sample to classify according to the two linear discriminant functions (LDFs) is given in Fig. 4 with a sensitivity and specificity of 90 and 100\%, respectively. The discrimination accuracy is 100\% (C666-1 and CNE2 each has one that is misjudged to the other, however, they are still abnormal). As can be seen from the scatter plot diagram, along with LDF1, tumor cell lines and normal cell line are separated into two groups. Tumor cell lines C666-1 and CNE2 can be distinguished from LDF2. This may indicate that LDF1 plays the leading role in the discrimination of tumor and normal cell lines while LDF2 mainly affects the discrimination between tumor cell lines.

\section{Conclusions}

In this study, we have demonstrated the ability of RS to distinguish between NPC cell lines C666-1, CNE2 and nasopharyngeal normal cell line NP69. The spectral ratio of $\mathrm{I}_{1449} / \mathrm{I}_{1657}(=1.10)$ seems able to 


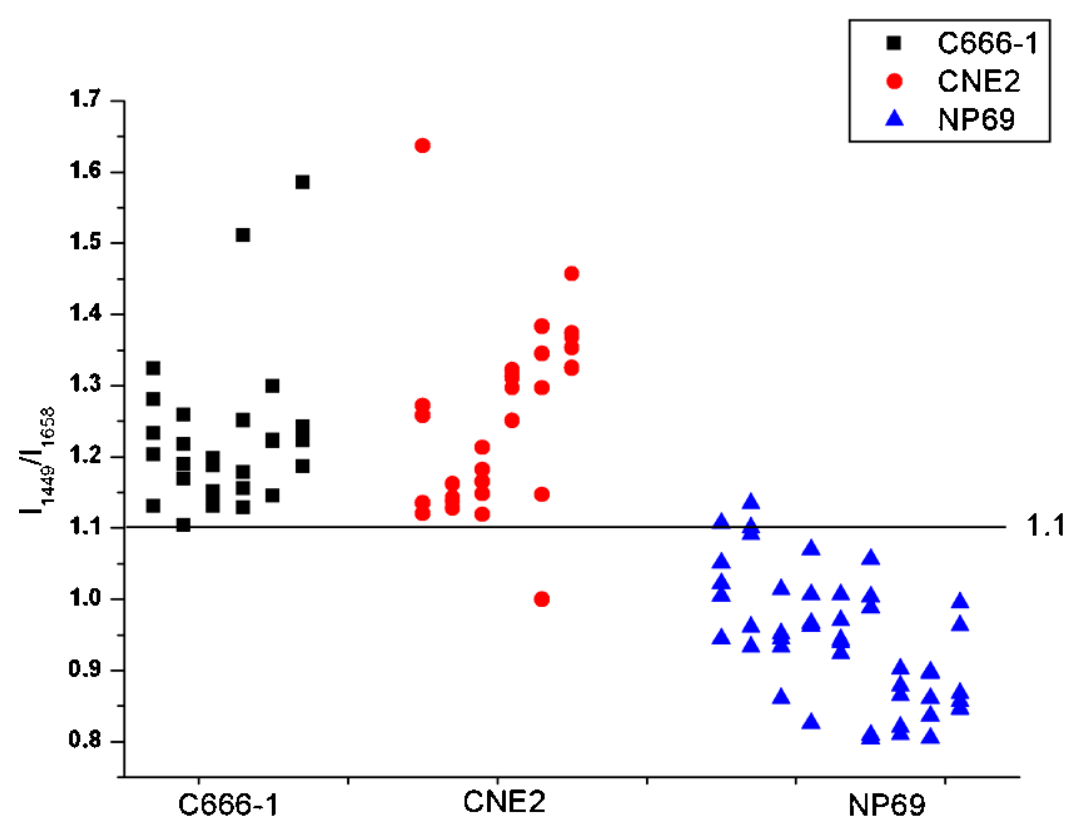

Fig. 2. $\mathrm{I}_{1449} / \mathrm{I}_{1657}$ of tumor and normal cell lines. (Colors are visible in the online version of the article; http://dx.doi.org/ 10.3233/SPE-2011-0511.)

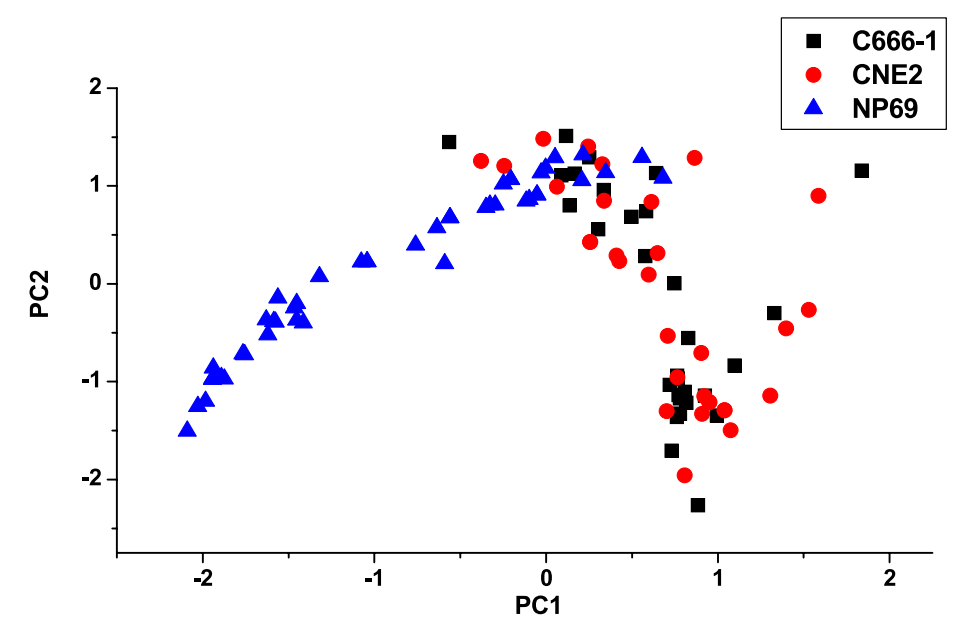

(a)

Fig. 3. Scatter diagram of first two PCs (2D) and first three PCs (3D). (Colors are visible in the online version of the article; http://dx.doi.org/10.3233/SPE-2011-0511.)

easily separate tumor and normal cell lines into two groups. In combination with multivariate statistical methods (PCA and LDA), RS allows the different cell lines to be separated with greater than $90 \%$ of accuracy. The results support the potential utility of Raman spectroscopy for nasopharyngeal diagnosis. 


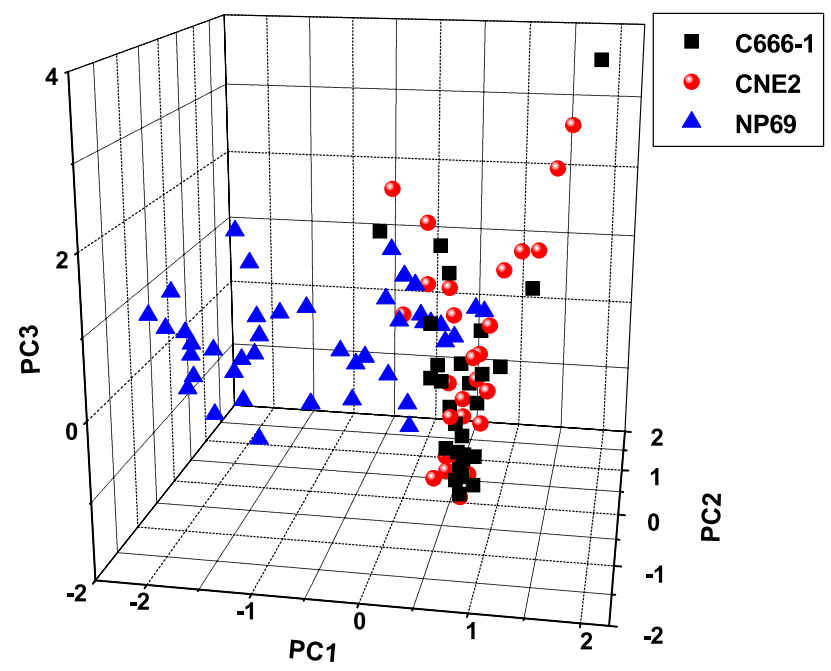

(b)

Fig. 3. (Continued.)

LDA of C666-1, CNE2 vs. NP69

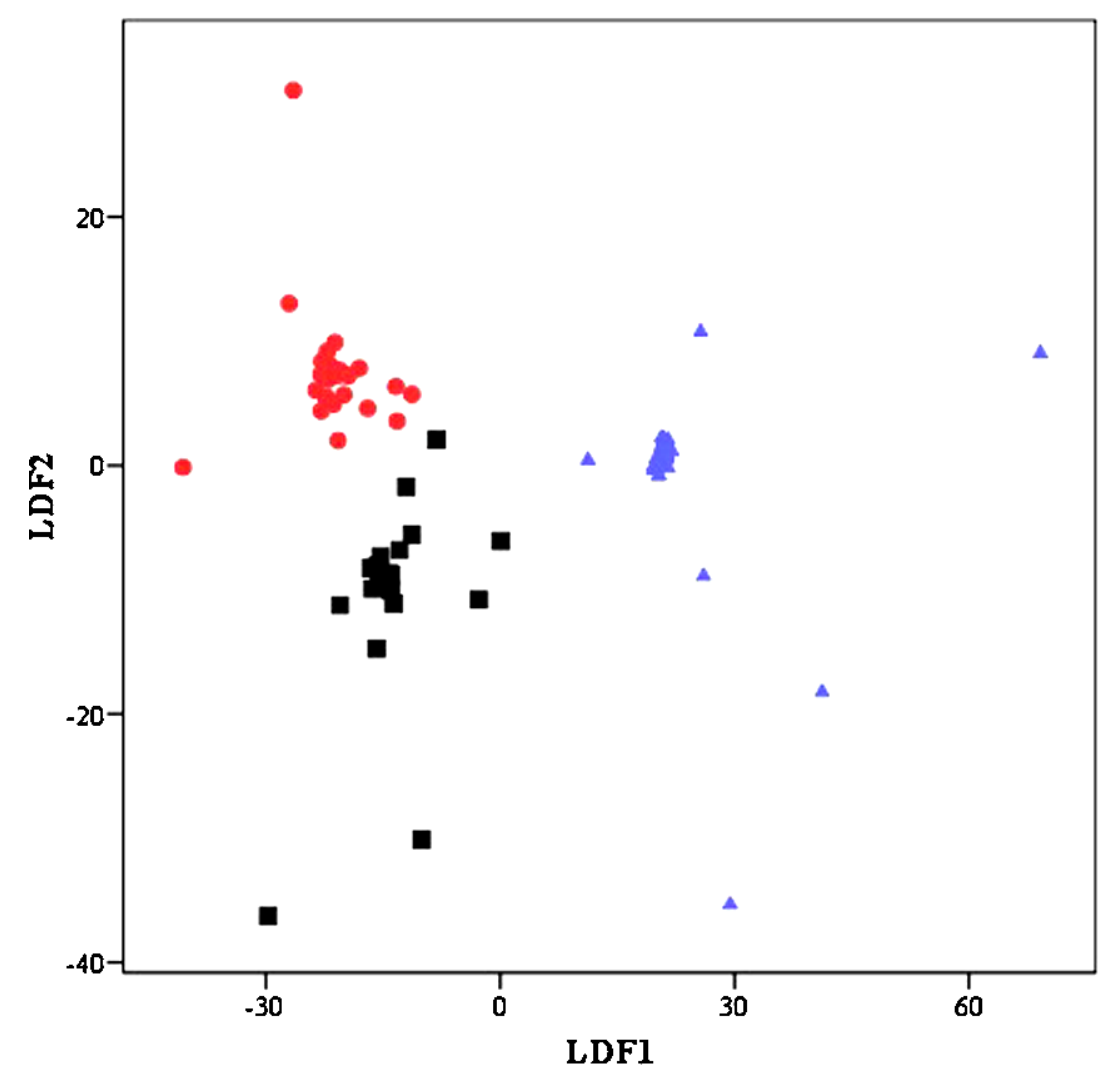

Fig. 4. Scatter plot of LDA demonstrating the clustering of tumor and normal cell lines. (Colors are visible in the online version of the article; http://dx.doi.org/10.3233/SPE-2011-0511.) 


\section{Acknowledgements}

This work was supported by the National Natural Science Foundation of China (No. 60778046), the Project of Science Foundation of Ministry of Health and United Fujian Provincial Health and Education Project for Tackling the Key Research (No. WKJ2008-2-046), the Project of Fujian Education Department (type B, No. JB08064) and the Canadian Institutes of Health Research International Scientific Exchange Program.

\section{References}

[1] K.L. Browna, O.Y. Palyvoda, J.S. Thakur, S.L. Nehlsen-Cannarella, O.R. Fagoaga, S.A. Gruber and G.W. Auner, Raman spectroscopic differentiation of activated versus non-activated T lymphocytes: An in vitro study of an acute allograft rejection model, Journal of Immunological Methods 340 (2009), 48-54.

[2] J.W. Chan, D. Taylor, T. Zwerdling, S.M. Lane, K. Ihara and T. Huser, Micro-Raman spectroscopy detects individual neoplastic and normal hematopoietic cells, Biophysical Journal 90 (2006), 648-656.

[3] J.W. Chan, D.S. Taylor and D.L. Thompson, The effect of cell fixation on the discrimination of normal and leukemia cells with laser tweezers Raman spectroscopy, Biopolymers 91 (2008), 132-139.

[4] P. Crow, B. Barrass, C. Kendall, M. Hart-Prieto, M. Wright, R. Persad and N. Stone, The use of Raman spectroscopy to differentiate between different prostatic adenocarcinoma cell lines, British Journal of Cancer 92 (2005), 2166-2170.

[5] P. Crow, N. Stone, C.A. Kendall, R.A. Persad and M.P.J. Wright, Optical diagnostics in urology: current applications and future prospects, British Journal of Urology International 92 (2003), 400-407.

[6] P. Crow, N. Stone, C.A. Kendall, R.A. Persad and M.P.J. Wright, The use of Raman spectroscopy to identify and grade prostatic adenocarcinoma in vitro, British Journal of Cancer 89 (2003), 106-108.

[7] J. de Gelder, K. de Gussem, P. Vandenabeele and L. Moens, Reference database of Raman spectra of biological molecules, Journal of Raman Spectroscopy 38 (2007), 1133-1147.

[8] K. Hamada, K. Fujita, N.I. Smith, M. Kobayashi, Y. Inouye and S. Kawata, Raman microscopy for dynamic molecular imaging of living cells, Journal of Biomedical Optics 13 (2008), 044027-1-4.

[9] https://internal.cbst.ucdavis.edu/education/courses/winter-2008-ead-bim-289/burger_jan_24_bioraman_afm.pdf/view? searchterm $=$ None.

[10] Z. Huang, A. Mcwilliams, H. Lui, D.I. Mclean, S. Lam and H. Zeng, Near-infrared Raman spectroscopy for optical diagnosis of lung cancer, International Journal of Cancer 107 (2003), 1047-1052.

[11] C.M. Krishna, G. Kegelaer, I. Adt, S. Rubin, V.B. Kartha, M. Manfait and G.D. Sockalingum, Characterisation of uterine sarcoma cell lines exhibiting MDR phenotype by vibrational spectroscopy, Biochimica et Biophysica Acta 1726 (2005), $160-167$.

[12] M.D. Mannie, T.J. McConnell, C. Xie and Y. Li, Activation-dependent phases of T cells distinguished by use of optical tweezers and near infrared Raman spectroscopy, Journal of Immunological Methods 297 (2005), 53-60.

[13] C. Matthäus, T. Chernenko, J.A. Newmark, C.M. Warner and M. Diem, Label-free detection of mitochondrial distribution in cells by nonresonant Raman microspectroscopy, Biophysical Journal 93 (2007), 668-673.

[14] D. Naumanm, FT-infrared and FT-Raman spectroscopy in biomedical research, Applied Spectroscopy Reviews 36 (2001), 239-298.

[15] I. Nothingher, G. Jell, P.L. Notingher, I. Bisson, O. Tsigkou, J.M. Polak, M.M. Stevens and L.L. Hench, Multivariate analysis of Raman spectra for in vitro non-invasive studies of living cells, Journal of Molecular Structure 744-747 (2005), 179-185.

[16] I. Notingher, S. Verrier, H. Romanska, A.E. Bishop, J.M. Polak and L.L. Hench, In situ characterisation of living cells by Raman spectroscopy, Spectroscopy 16 (2002), 43-51.

[17] W.L. Peticolas, Raman spectroscopy of DNA and proteins, Methods in Enzymology 246 (1995), 389-416.

[18] G.J. Puppels, F.F.M. de Mul, C. Otto, J. Greve, M. Robert-Nicoud, D.J. Arndt-Jovin and T.M. Jovin, Studying single living cells and chromosomes by confocal Raman microspectroscopy, Nature 347 (1990), 301-303.

[19] G.J. Puppels, H.S.P. Garritsen, G.M.J. Segers-Nolten, F.F.M. de Mul and J. Greve, Raman microspectroscopic approach to the study of human granulocytes, Biophysical Journal 60 (1991), 1046-1056.

[20] C. Xie, N. Nguyen, Y. Zhu, Y. Li, Detection of the recombinant protein in single transgenic microbial cell using laser tweezers and Raman spectroscopy, Analytical Chemistry 79 (2007), 9269-9275.

[21] H. Yao, M. Zhu, G. Wang, G. Wang, L. Peng, B. He, M. He and Y. Li, Study of Raman spectra of single carcinoma of nasopharynx cell, Guang Pu Xue Yu Guang Pu Fen Xi 27 (2007), 1761-1764 (in Chinese). 
[22] C. Yu, E. Gestl, K. Eckert, D. Allara and J. Irudayaraj, Characterization of human breast epithelial cells by confocal Raman microspectroscopy, Cancer Detection and Prevention 30 (2006), 515-522.

[23] J. Zhao, H. Lui, D.I. Mclean and H. Zeng, Automated autofluorescence background subtraction algorithm for biomedical Raman spectroscopy, Applied Spectroscopy 61 (2007), 1225-1232. 


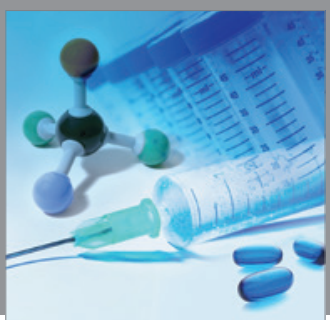

International Journal of

Medicinal Chemistry

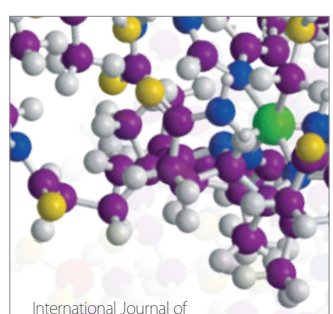

Carbohydrate Chemistry

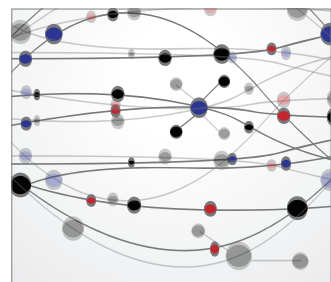

The Scientific World Journal
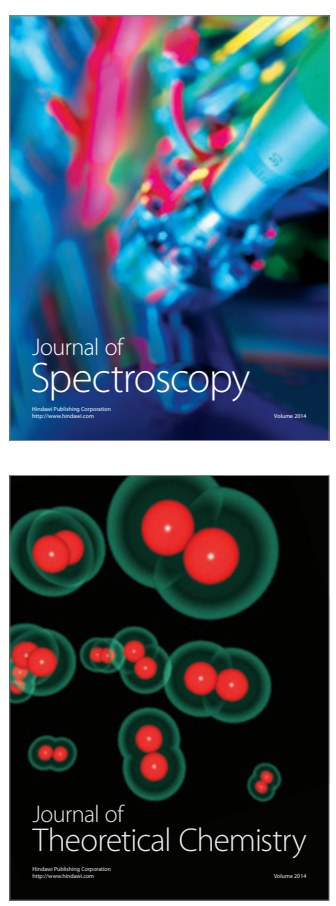
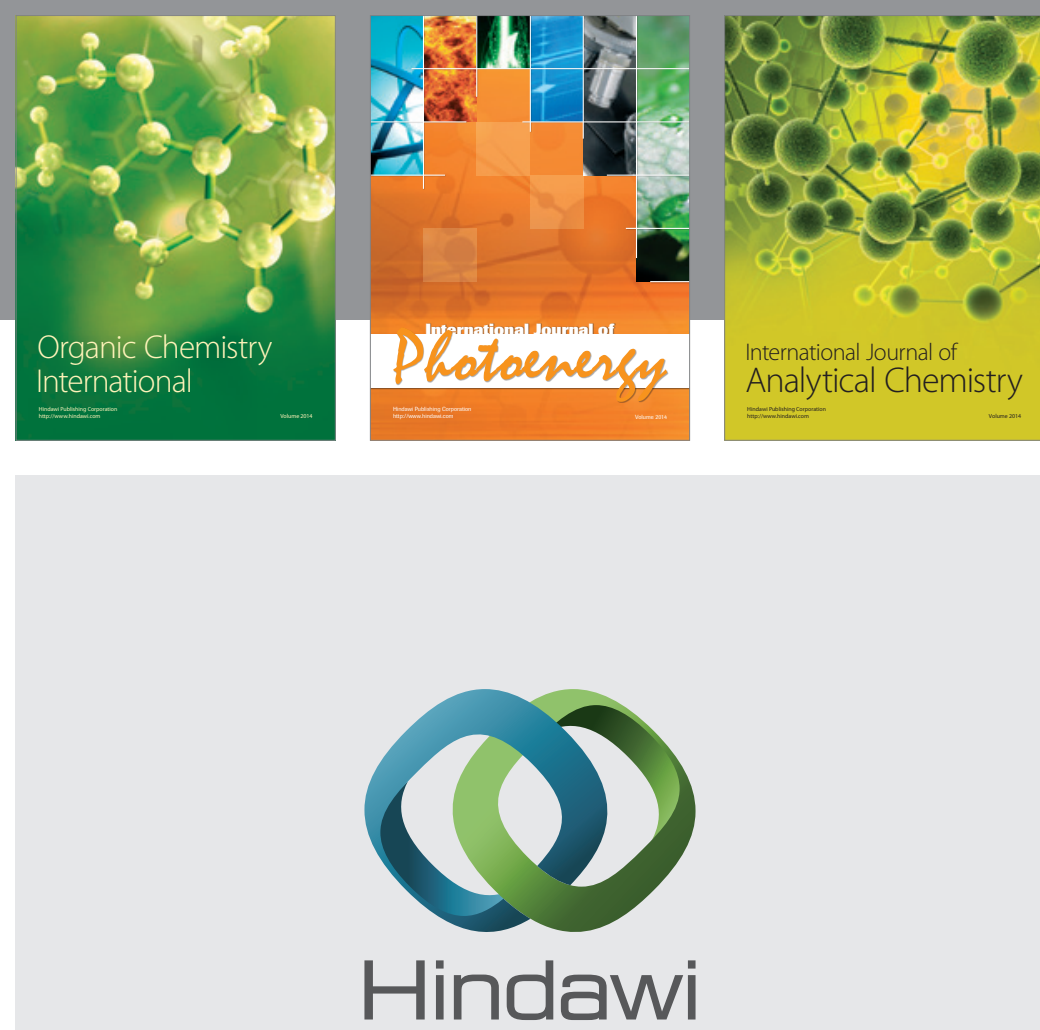

Submit your manuscripts at

http://www.hindawi.com
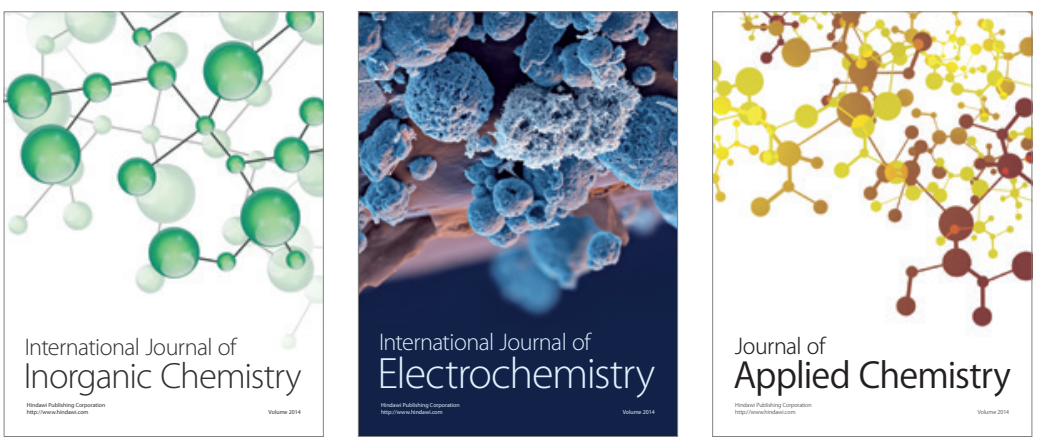

Journal of

Applied Chemistry
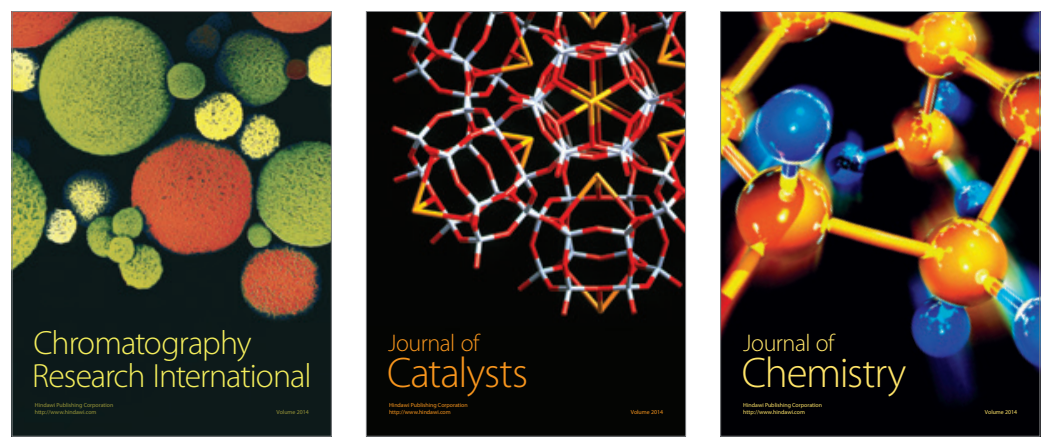
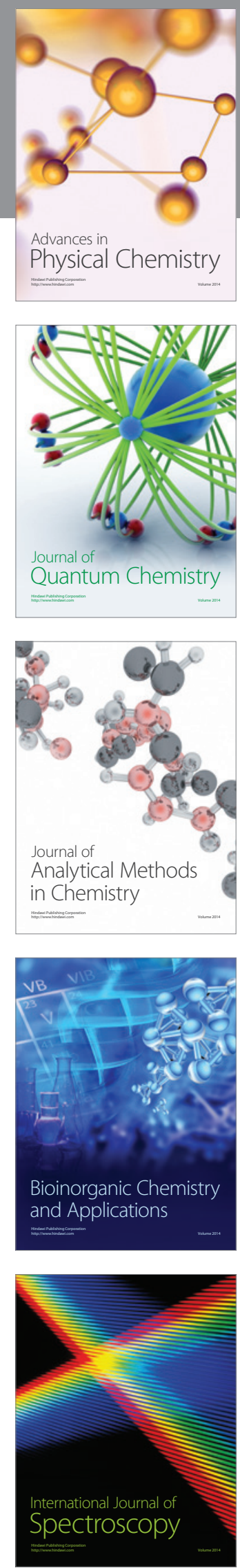